\title{
Tourism Policy and Residents' Well-being in Cyprus: Opportunities and Challenges for Developing an Inside-Out Destination Management Approach
}

\author{
Nikolaos Boukas \& Vassilios Ziakas
}

Published in: Journal of Destination Marketing and Management

\begin{abstract}
The paper explores how Cyprus can increase its competitiveness, sustaining its magnitude and attractive attributes, and ensuring residents' well-being. The study evaluates the suitability of an 'inside-out' planning approach to island tourism development. Eleven interviews were conducted with tourism policy-makers and stakeholders complemented by documentary analysis of official policy sources. Findings indicate that Cyprus tourism policy addresses only indirectly residents' well-being, and therefore a policy re-orientation focusing on local prosperity is needed. It is proposed that an 'inside-out' approach stemming from the kind of development that locals want for improving their quality of life can foster islands' socio-cultural revitalisation. An 'inside-out' approach can redirect Cyprus tourism policy to focus on alternative forms of tourism such as rural/special interest tourism. However, to reconfigure its tourism product, Cyprus should remedy the 'top-down' and bureaucratic planning processes that create challenges for the sustainable development of tourism. The adoption of an 'inside-out' approach can enable 'bottom-up' decision-making by empowering residents to partake in local communities' tourism planning intending to improve life quality. Broadly, these conditions need to be further examined within the context of small island destinations in order to find the means for implementing their repositioning/rebranding driven by a local focus aimed at enhancing residents' wellbeing.
\end{abstract}

Keywords: Residents well-being, islands, Cyprus, inside-out tourism development, bottom-up planning, sustainability 


\section{Introduction}

Islands depending upon their position, physiognomy and cultural features can be considered as attractive destinations of extensive (and sometimes unregulated) tourism development (Bastin, 1988; Ioannides, 1992; Boukas \& Ziakas, 2013a). Nonetheless, their small size and special characteristics (remoteness, limited resources, lack of diversified economy, etc.) make them over-reliant on foreign investment(s). In this regard, the global capitalist system tends to control decision-making regarding their tourism development (Butler, 2011; Lewis-Cameron \& Roberts, 2010) leaving therefore their future on non-local hands and overlooking the needs and well-being of local people.

At the same time, the majority of these islands are developed mostly as mass tourist seasonal destinations that strive to be competitive, sacrificing though their precious resources and balanced development. In a highly competitive environment, islands need to face several problems, the majority of them related to limited resources (i.e., water, space, workforce, etc.), segregation, and dependency on the rest of the world (Niles \& Baldacchino, 2011). This does not only pose challenges for the sustainability of their local natural, socio-cultural, and economic fabric but also makes them susceptible to the tensions and crises that manifest at a worldwide level. What seems therefore as a possible response in the case of islands, and warrants investigation, is the need to re-orient their tourism policy focus from merely meeting the needs of foreign tourists ('outside-in') to catering for the well-being of local people ('inside-out'). An 'inside-out' approach means that strategies should not be driven from something needed from the outside (tourists) but rather from something that locals want for themselves in order to improve their well-being (Ziakas \& Costa, 2010). This has the potential to enhance the tourism superstructure of an island destination and its overall attractiveness, thereby generating tourist 
flows and contributing to its sustainability contingent upon the efficient deployment of the available destination capitals (Sharpley, 2009).

Cyprus, as a small island state, exhibits all the above characteristics that necessitate a turn in tourism policy in order for resolving the range of problems it faces. Specifically, having invested in mass tourism since 1960s, Cyprus currently faces problems of decreased competitiveness, lack of service quality in the hospitality sector, monothematic development (almost 2.3 million tourists per year visiting mostly five coastal areas especially during the summer period), reliance on foreign capital, and decline of tourist flows (Archontides, 2007; Boukas \& Ziakas, 2014). As the effects of the global economic crisis in 2008 and the banking collapse of 2013 have dramatically deteriorated the conditions for prosperity on the island, tourism policy-makers/stakeholders strive to find solutions for the speedy recovery and the remapping of Cyprus as a significant Mediterranean island destination. In parallel, the whole tourist system is still based on the mass tourism model that for years underestimated the necessity for sustaining its limited resources and created problems that threaten the island's future viability and the residents' well-being. In this context, is an inside-out tourism approach feasible for Cyprus and under what conditions could be developed?

To answer this question, the paper explores how Cyprus can increase its competitiveness and deal effectively with the challenges of the economic recession, maintaining its magnitude as an attractive site, on the one hand, but at the same time sustaining its attributes for future generations and ensuring the well-being of its residents and stakeholders. In doing so, the paper examines the island's resilience by focusing on the factors that determine the extent to which current tourism development plans, which are primarily responding to crisis, affect Cyprus economic, social and environmental sustainability. This examination can reveal potential 
linkages between tourism policy and residents' well-being, which can enable an 'inside-out' approach in tourism development strategies. Finally, the paper proposes theoretical and practical implications in order for islands as destinations with unique characteristics and peculiarities to successfully invest in their qualities that will give them the independence to make their own decisions ensuring the local community's long-term prosperity as well as their future growth and development.

\section{Island tourism and sustainable development: an unanswered query?}

Islands' exceptional characteristics such as their morphology, climate, genuine natural and cultural features as well as landscape and setting made them successful tourist destinations (Carlsen \& Butler, 2011; dos Santos, 2014; Lewis-Cameron \& Roberts, 2010). Indeed, the fact

that islands were always considered as fascinating places, physically separated from the continent world, with many differences and exotic elements, ideal for 'escape' and open to 'otherness' (Sharpley, 2012), contributed towards their transformation into unique destinations offering desirable experiences to tourists. Moreover, the economic contribution of tourism was considered by islands' tourism policy as one of the most important motives to systematically deal with the tourist activity (Currie \& Falconer, 2014; Pratt, 2015; Sharpley \& Ussi, 2014; Seetanah, 2011) and capitalise on its financial benefits.

In this regard, islands such as those in Mediterranean, Caribbean and South Pacific have become powerful destinations in the world's tourism sphere (Butler, 2008; Croes, 2011; Hadjikakou et al., 2014; Pratt \& Harrison, 2015). For instance, Greek islands have been considered as the top destinations in the Mediterranean (Paci \& Marrocu, 2014). 
Characteristically, from the 12.302 .448 tourists that arrived at Greece by air in 2013, the 7.491.305 (almost the 61\%) arrived only at seven island airports (Zante, Heraklion, Corfu, Kos, Rhodes, Santorini, Chania) (Greek Statistics, 2014). This signifies the power of island tourism for the entire country. Indeed, since 1960s, Greek islands are considered as major destinations, mostly for mass summer tourism (Graci \& Dodds, 2010; Tsartas, 2003); due to tourism's economic significance, Greek islands have been developed in such a way to satisfy mass tourist expectations. It is quite obvious therefore, that the majority of islands as destinations within the Mediterranean basin have been planned to satisfy mostly mass tourism needs (Aretano et al., 2013). The fact that islands offer unsparingly all the basic ingredients of mass tourism (sea, sun, sand) led to the creation of a whole industry around this model (resort hospitality industry near the sea). However, the same characteristics that make islands attractive destinations (remote places surrounded by the sea), could also be weaknesses for their overall development. As Niles and Baldacchino (2011) argue, islands are characterised as places with rich and diverse flora/fauna but at the same time they face important resource deficiency, segregation, and dependency on the rest of the world. The authors conclude that due to this situation, islands struggle to balance two contradictory forces: (a) to keep their ecological integrity, and (b) to strive for the economic development and community quality of life, especially considering the urgency to preserve their social/spatial characteristics. Under the sphere of mass tourism development, this balance is hard to be achieved and maintained. One the one hand, the contribution of mass tourism to islands' economic development and prosperity is recognised, but on the other hand, the negative impacts of this form of tourism such as monothematic development, seasonality, resource depletion, and crowdedness hinder the overall effort for reaching an equilibrium. Consequently, islands need to face problems such as climate change 
(Keener, 2013), seasonality (Ridderstaat et al., 2014), and scarcity of resources (Boukas, Boustras, \& Sinka, 2012; Stathatou et al., 2015) while dealing with dependencies on the global economy and tourism (Sharpley, 2012). This raises challenges regarding the overall sustainable development of islands (Graci, 2013; Graci \& Dodds, 2010; Jaafar \& Maideen, 2012) and makes us wonder if it is realistic to discuss about sustainable tourism in the case of islands, where natural, social as well as economic resources, are limited.

In economic terms, Lewis-Cameron and Roberts (2010) claim that islands are highly dependent on foreign ownership to foster their tourism superstructure. Moreover, the authors add that for islands, indigenous people are on the bottom of the pyramid concerning not only ownership but also employment. The lack of financial power by locals to sustain large-scale projects such as hotels and/or hospitality establishments contributes to this situation. Along the same lines, Carlsen and Butler (2011) suggest that islands as destinations have several dependencies on external forces and together with the reduction of other traditional economic activities (i.e., agriculture) as well as their geographical isolation, they are more vulnerable to crises. Therefore, the economic sustainability of islands under the prism of tourism is difficult to be guaranteed and maintained.

In environmental terms, the sustainability of islands is also debatable. As Boukas and Ziakas (2013a) suggest, islands are sensitive ecosystems characterised by limited resources such as geographical disparity, limited space as well as, in the case of southern island destinations, long dry climate and limited water supplies. Additionally, the excessive development of tourism alters in a high degree islands' carrying capacity and brings several negative impacts. Such negative impacts encompass deforestation, loss and wild life elimination (Lean 1994), pollution of shores, and reef destruction (Robbins 1994). Moreover, as McElroy and de Albuquerque 
(1998) claim in their study about tourism penetration in small Caribbean islands, two main trends have occurred since the post-1960 tourist restructuring of Caribbean island microstates: a) the older more successful destinations have sacrificed their socio-environmental constancy for the sake of bottom line economics; b) even with the previous trend, newer destinations appear to incline towards the same unsustainable tourism development of mass tourism. As such, more and more developments for tourism are taking place in the limited space of islands (i.e., resorts, hotels, etc.), that not only supplement other economic activities but also invade on islands' fragile biodiversity.

Finally, in social terms, the excessive development of tourism on islands can have negative effects. For instance, in the case of the Eastern Mediterranean islands of Mykonos, Crete, Rhodes and Cyprus it has been noticed that locals have constructed a great number of illegal buildings (Lim \& Cooper, 2009). Furthermore, an important social impact on islands is the pressure that tourist crowds cause to destinations because of the over-congestion in certain places, construction of infrastructure that damages natural resources, and the misuse of water (Gutiérrez, 2015; Rodríguez, López, \& Estévez, 2008). Specifically, in the case of Cyprus, Boukas et al. (2012) argue that in an effort of Cypriot tourism policy to construct several golf courses as a strategic response for redressing the high seasonality that the island faces, a series of contradictions were raised. Firstly, the usage of a significant amount of water for maintaining the golf courses was dramatically increased at the same time where water is many times scant in the dry Eastern Mediterranean climate of Cyprus, creating thus threats for the prosperity of the island's residents. Secondly, the development of golf courses needs space, which is limited in the case of islands. In different circumstances, this space could be used for other types of development that would enhance more efficiently the life quality of locals. Finally, the 
development of golf tourism in Cyprus, created a series of contradictions at a community level, since a portion of the stakeholders (i.e., hoteliers) considered that the overall development is not about tourism, but about real estate, since together with the golf courses several big projects (i.e., housing) are built on the island creating unbalanced development.

Therefore, even if tourism is considered important for the economic growth of islands (Ridderstaat, Croes, \& Nijkamp, 2014), sometimes tourism development threatens sustainable stewardship of islands' limited resources and their socio-cultural character. Furthermore, the over-reliance of the island economies on tourism, raises queries regarding how they can become competitive destinations without forfeiting their natural character and harming their sociocultural fabric in the long-term. Moreover, it is also important to examine the contribution of the indigenous people in the overall tourist policy making of islands and clarify their role as receivers of enormous -for their size- developments.

\section{An inside-out approach in destination tourism development and community well-being}

The aforementioned characteristics of islands justify why tourism is an important activity for the majority of their residents. Though, a serious matter raised is to clarify how 'powerful' indigenous people are, to make their own decisions regarding local tourism development, and in the end, can they control it? As Sofield (2003) suggests, according to World Tourism Organisation (WTO), the development of tourism is synonymous to the over-growth of facilities, infrastructure, attractions, etc. as well as the education of locals about the positive impacts of tourism. The majority of these activities are tourist-oriented and aim to provide an appealing tourist experience that will lead to overall satisfaction. However, in an effort to please tourists' demands it has been noted that many resources (i.e., cultural character) are sacrificed. This 'outside-in' approach is quite evident in contemporary tourism (Zhang, Yamamura \& Fujiki, 
2013). Furthermore, Sofield (2003) argues that while public involvement in tourism planning is noted, it presupposes that their (re)action about tourism will be positive and eventually, it is questionable if their contribution is really active towards their own benefit.

In this regard, it is clear that the approach that WTO adopts about tourism development is more towards 'top-down' decision-making. Even though, the 'bottom-up' approach, or the approach that recognises local communities' involvement towards setting their own goals and decision-making about the utilisation of their resources (i.e., heritage preservation, development of buildings, etc.) (Kelly \& Becker, 2000) and then incorporates it into the regional or national planning, is identified by WTO, it is quite obvious that its application is hard to be achieved. Indeed as WTO claims (Sofield, 2003), several contradictions among local stakeholders as well as the various policies and development recommendations, that accompany the 'bottom-up' approach, make it time-consuming and ultimately, these conflicts need to be reconciled at the national level for the formation of a consistent plan. As such, even though the value of community participation in the overall destination planning is recognised, it is evident that their actual contribution is questionable.

Under the premises of sustainable development, matters regarding the degree to which tourism benefits the overall residents' interests (economic, social, environmental, and cultural) are raised and have to be clarified. Moreover, emphasis needs to be given to a destination's all tourism stakeholders that are largely based on residents' perceptions. Thus, it is important to examine residents' perceptions for the types of tourism investment plans and associated policy measures that could support tourism development strategies (Azzopardi \& Nash, 2015; Boukas \& Ziakas, 2013a; Del Chiappa \& Abbate, 2015). The incorporation of an 'inside-out' approach in destination tourism development would lead towards this direction. 
According to the 'inside-out' approach of development, a community follows its own paths of growth, and tourists visit mostly to enjoy and learn from the local wisdom (Zhang, Yamamura, \& Fujiki, 2013). In contrast to the 'outside-in' approach, local communities are at the epicentre of attention while planning tourism. As Wilson (1996) maintains, this 'inside-out' approach is based on the individual's realisation of self-efficacy and interconnectedness with the larger community while the role of individual as a subject and not an object is of crucial importance for the community empowerment, economic development and social change. As such, the 'inside-out' approach is seen as a micro-perspective (in contrast to the macroperspective of 'outside-in' approach) that adopts a narrow view of the environment as reflected in organisational needs and internal influences, while its emphasis is shorter in time horizon and incorporates fewer environmental characteristics (Jogaratnam \& Law, 2006). In this respect, the development of a locally-responsive tourism plan could be better achieved by understanding the needs, beliefs and concerns of local communities, thereby adopting the 'inside-out' approach and fostering 'bottom-up' strategies of tourism development for destinations that may compete within the world's tourist arena.

Moreover, despite that tourism is a global phenomenon with great magnitude and therefore worldwide character (Cole, 2009; Shaw \& Williams, 2004; Theobald, 2005), its consumption takes place in a local context that is significantly (re)structured by global influences which command product/service varieties and diversity (Meethan, 2001). This raises the issue whether the globalisation of tourism is a force of homogenisation or diversity (Chang, Milne, Fallon, \& Pohlmann, 1996; Meethan, 2001; Teo \& Li, 2003). As Gotham (2005, p. 311) states: 
'The generalized processes of commodification and homogenization that characterize the international tourism industry are not monolithic but are mediated at various spatial and institutional levels, from the macro-level of globalized institutions to the micro-level of people's day-to-day lives'.

Therefore, in this equation the role of local residents is important. According to Gotham (2005), locals are able not only to transform and (re)arrange global tourist trends of homogenisation, standardisation and commodification, but also to actively involve (together with tourists) in the production of novel meanings for the destination. The author concludes that locals have the power to give meaning(s) to the global forces of commodification and to express them to a local level. In this regard, the 'inside-out' approach needs to be adopted for understanding locals' perceptions, even in places characterised by significant global tourism change. Since locals are powerful to construct their own tourist environment, 'bottom-up' directions in tourism development are important for enhancing their community well-being.

For this reason, the role between tourism and the well-being of community needs to be better shaped. According to Kusel and Fortmann (1991), community well-being is associated with the social, economic, cultural and political elements that maintain a community and satisfy the needs of their residents. In terms of tourism, Buzinde, Kalavar and Melubo (2014) argue that tourism activity influences well-being in a negative (i.e., abandonment of traditional activities) but also a positive (i.e., economy, status, etc.) way. Indeed, well-being is tightly connected to the happiness of a community's members. According to Nawijin and Mitas (2011), in their study about resident attitudes to tourism in Palma de Mallorca, perceived tourism impacts and more specifically the life domains of health, interpersonal relationships, friends and services and 
infrastructure, are connected to the subjective well-being of residents since they boost their happiness. However, the level of perceived impacts of tourism on the well-being of locals may vary. For instance, Ribeiro, Valle and Silva (2013), studying residents' attitudes towards the development in Cape Verde Islands, identified three segments of residents, suggesting different perspectives according to the way the tourism impacts are perceived: 'optimistic residents', 'rational residents' and 'indifferent residents'. According to the authors, 'optimistic residents' recognise that tourism has more positive rather than negative impacts on the destination. 'Rational residents' have a reflective attitude about the benefits and costs of tourism. Finally, 'indifferent residents' recognise less the benefits of tourism (social, cultural, environmental) but at the same time they do not value that this activity will bring important costs.

Nonetheless, even though tourism is a means for boosting an individual's satisfaction and hence well-being, the majority of efforts has been put on understanding tourists' perceptions while it systematically neglects to explore local population' component of life satisfaction and its relationship to tourism (Nawjin \& Mitas, 2012). Despite the power of locals to construct their own environment among global forces, little attention has been given to examine how indigenous people of a destination can influence political decision-making and planning for tourism development. Considering under the prism of sustainability, that a destination would be successful if it provides benefits to both tourists and locals in the long-term, and that islands as idiosyncratic destinations with their own anthropography and distinctiveness need to be developed and managed sustainably, an orientation towards the 'inside-out' approach on tourism development could enhance the positive perceived impacts of tourism and reduce its negative ones. 


\section{Methodology}

This study was part of a larger research that examined Cyprus tourism development and its relationship to sustainability. Findings from this research indicated the characteristics of the island's tourist system and diachronic processes of mass tourism development that hinder its sustainability (Boukas \& Ziakas, 2014) as well as the policy responses to redress the impacts of the global economic crisis on Cyprus tourism (Boukas \& Ziakas, 2013a). Further, findings illustrated, on the one hand, opportunities for diversifying the tourism product such as golf tourism (Boukas \& Ziakas, 2013b) and event tourism (Ziakas \& Boukas, 2013), but on the other, showed the inherent problems of making a substantial contribution to the sustainable development of the island. This research also revealed the intention of the Cyprus tourism policy to improve the well-being of the indigenous population, which is currently unexplored and thus instigated the undertaking of this study.

Due to the focus of the study on policy development, a qualitative approach (Yin, 2009) was chosen for the investigation of the relationship between Cyprus tourism policy and residents well-being. This entailed elite in-depth interviewing of policy-makers and tourist stakeholders supplemented by documentary analysis of official policy sources. Specifically, semi-structured interviews were employed, as they allow more detailed information to be gathered, by providing an opportunity for the interviewer to probe and expand the interviewee's responses (Weiss, 1994). Additionally, documentary analysis of pertinent policy publications and reports was undertaken in seeking to discover, describe or map patterns and trends in tourism policy-making relating to residents well-being. The ultimate purpose of examining documents is to arrive at an understanding of the meaning and significance of what the document contains (Scott, 1990). In essence, this process entailed an interpretive understanding of the literal meaning related to the 
contexts in which the documents were produced in order to assess the meaning of the text describing government tourism policies as a whole.

Eleven interviews were conducted with tourism officials and stakeholders (Table 1). Data were collected for this research from the summer of 2013 until the spring of 2015 in order to obtain a variety of representative responses that take into account the effects of the economic crisis and subsequent socio-political instability. This two-year period of data collection entailed follow-up interviews, thereby allowing a continuous critical reflection of the issues that surfaced in Cyprus and how they have affected residents' quality of life.. This purposive sampling of high-rank administrators aimed to draw knowledge from the most informed actors who influence tourism policy in Cyprus. Elite interviewing provides a rich and thorough source of data as top executives hold strategic knowledge (King, 1994) and can express their ideas/experiences (Arksey \& Knight, 1999). In this regard, the basic criterion for the selection of interviewees was that they hold a key position in organisations responsible for development and implementation of tourism policy.

\section{TABLE 1}

The interviews were conducted in the offices of the interviewees and their length ranged between 40-60 minutes. Follow-up interviews were arranged and conducted with all interviewees to clarify policy changes and the undertaking of new measures. An interview guide was used for the initial and follow-up interviews to provide a focus for the questions (Table 2) while probes were used to elicit in-depth responses. Furthermore, policy documents were examined comparatively to triangulate the interpretation of interview findings and documented measures 
and strategies (Grix, 2001). Since this study was part of a larger research, data collection was constantly informed from the overall pool of data.

\section{TABLE 2}

All the interviews were recorded and transcribed verbatim in the Greek language. Thereafter the interview transcripts were translated in English and analysed manually by both authors following a reiterative, interpretive process that made constant comparisons with other interviews, documents and literature to draw out meaning and ensure internal validity. Content analysis employed a directed approach using pre-determined categories for the coding scheme (Silverman, 2001). The coding scheme was adopted to fit the purpose of the study by examining the context of tourism development and sustainability in Cyprus, its correlation with residents' well-being as well as the role of pertinent policy measures for local quality of life. Hence, the thematic categories were the following: 1) Tourism development and sustainability in Cyprus, 2) Tourism and residents' well-being, and 3) Tourism policy measures. This structured approach allowed to categorise data systematically and incorporate new insights that relate closely to the topic under study. Data that did not fit the coding scheme were categorised as alternative themes. All the results were checked for validity and consistency by comparing them with the previous studies and also by going back to the general literature. This helped to enhance the reliability of the findings and thus substantiated their meaning and significance for policy-making within the context of small island destinations. 


\section{Findings}

\section{Tourism development in Cyprus and sustainability}

To account for the formulation of Cyprus tourism policy and its implications for residents' wellbeing, it is essential to contextualise first the evolution of the tourism industry on the island since its independence and the driving forces that affect the sustainability of tourism development. Specifically, tourism development in Cyprus and its relationship to sustainability has been as problematic as the political and ethnic struggle on the island. As mentioned in the interviews:

'Tourism in Cyprus slowly began in 1960s, it was suddenly interrupted in 1974 with the invasion [Turkish] [...] and in the decades of 1980s-1990s it started to take off until 2001. Since then a decreasing pace followed, where we started considering what we need to do for this product'.

Apparently, Cypriot tourism has been developed within a context where serious social, political and economic pressures, demands, and changes have taken place. These forces have created severe problems constraining sustainable development. However, due to the apparent stability of the sector for almost 30 years, the problems were overlooked and have not effectively been addressed by tourism policy.

Specifically, after its independence from Great Britain, Cyprus policy-makers realised that tourism could generate substantial short-term revenues to the new-born state, contributing thus to its economic development. Consequently, there was investment in mass tourism exploiting the resources of the island and providing short-term economic benefits to the developing state. However, this period was rapidly interrupted by the Turkish invasion in 1974. Tourism as a highly sensitive sector suffered since $65 \%$ of the total bed capacity and $96 \%$ of 
beds under construction were located on the occupied part and therefore, got lost (Saveriades, 2000). The recovery from the invasion entailed a redesign of the overall Cypriot tourism system but again was based on the same model as before investing in mass tourism on the coastal areas of the free part of the island. Thus, coastal tourism and unlimited exploitation of the island's natural resources became the key drivers for the island's tourism growth, which constrained its sustainable development. While mass tourism appeared to deliver the expected benefits for almost three decades, since 2001 tourism has steadily been decreasing and several problems are now visible. As indicated:

\begin{abstract}
'Although we knew that there were several problems, a steady increase in tourism arrivals and revenues was evident until 2001. Since then however we have been having a gradual decrease. This means that Cyprus has lost its competitive edge. Our tourism product is almost obsolete, while many competitors now exist. Also, the inadequate infrastructure weakens our destination image. All these problems are diachronic but we just have started looking at them when the economic crisis occurred'.
\end{abstract}

The advent of the economic crisis in Cyprus instigated a necessary re-orientation of the national tourism strategy. The new orientation is related to the shortening of the tourism strategy's timehorizon and enforcing the accountability of pertinent organisations for improving the tourism product's quality. As explained:

'The major change in tourism planning concerns the new five-year strategy. The previous plan was for 10-15 years. In today's conditions you cannot plan for many years ahead because the changes are rapid. The new strategy identifies the priorities/responsibilities for upgrading the tourism product's quality, and keeps respective organisations accountable for that'. 
This change in policy aimed to set a basis for creating more flexible plans that can respond to changing needs and circumstances. An inherent problem that hinders sustainable tourism development is the dilemma between stewardship and competitiveness. Specifically, a common pattern is the over-use of limited natural/cultural resources by the tourism system in order to make the destination more attractive. This is evident in Cyprus in areas that face mass tourism and its negative consequences (e.g., Ayia Napa). Hence, the stewardship of the resources is an important variable to be considered during tourism planning on islands. This needs to be implemented under a comprehensive strategy, incorporating all the major stakeholders, and neutralising conflicts, discrepancies and contradictions. Emphasis on the understanding of the stakeholders' various goals and their contribution in tourism planning is important not only for making tactical decisions but also for designing high quality tourism products for the future.

Therefore, the Cypriot tourism policy-makers introduced certain strategies to counterbalance the negative impacts of the crisis. These were centred on three areas: (a) the pause by local authorities from receiving the taxation fees charged on the accommodation overnights/restaurant services for two years, (b) the pause of the government share from the airport fees for reducing the ticket prices, and (c) the introduction of a social tourism plan targeting domestic tourists (according to the interviews with policy representatives). The social tourism plan is one of the first measures that focus on the well-being of the indigenous population. However, its effectiveness is questionable as it has not been supported from further initiatives. Thus, the aforementioned measures were rather short-term reactions on the longlasting problems of the Cypriot tourism product. As such, the problems of Cyprus tourism remain the same. According to a respondent: 
'Even though there is a policy framework that underlines the need towards sustainable development, there are many setbacks. Among the reasons that this policy is not implemented are bureaucracy, the delay on many projects, the involvement of many stakeholders from the private and public sectors in decisionmaking, and the unattractive environment that these issues project to investors'.

Almost all the respondents emphasised the need for tourism policy to turn towards sustainable practices so as to resolve the problems that beset Cyprus. Economic crises such as the 2008 global one and the subsequent economic recession necessitate the adaptation of a sustainable policy framework that would facilitate the tourism system to recover. Although Cypriot tourism policy recognises the importance of heading towards sustainability, this is not realistically implemented through comprehensive and meticulous strategic planning, while the on-going crisis exacerbates the unsustainable state of tourism development on the island. Instead, the Cypriot tourism policy seeks to refine the tourism product by focusing on the improvement of quality loosely linked to sustainable development. As an official explained:

'Our new strategy defines quality in relation to sustainable development incorporating all the special forms of tourism that complement the tourist activities. For example, we have the project entitled 'Cyprus: all-year destination' that aims to extend the tourist season, and additionally, we add a variety of new specialised activities in order for tourists to choose visiting Cyprus'.

Overall, the findings indicate that sustainability is a growing concern for policy-makers but a more pragmatic direction is needed for enabling the tourism sector to contribute to the sustainable development of the island and foster residents' prosperity.

\section{Tourism and residents' well-being}


Based on the findings, sustainability is valued by tourism policy as an important direction that Cypriot tourism should follow. Indeed, sustainability provides a framework under which residents' prosperity can be achieved. However, tourism planning rarely incorporated locals in the past, not even in the formation of the tourism product. As stated by a respondent:

'Even though locals were theoretically considered as an important element of the Cypriot tourism product, there was no particular effort from tourism policy and stakeholders to address their needs and concerns.

Indeed, according to interviewees, locals were mostly treated as the means or the element of the tourism product that would enhance tourist experience. As such, the overall planning was highly centralised and geared towards achieving tourist satisfaction. This essentially maintained a diachronic 'top-down' decision-making and cultivated hence, an 'outside-in' approach of tourism development, while locals were never seriously considered as an important stakeholder in the overall tourism planning process. As stated:

'I believe that deep inside the minds of the islands' tourist stakeholders lies the principle for tourists to have a good time. We say that the local community benefits, but mostly because of the economic impacts that international tourists bring to Cyprus. What is missing is the locals' voice on how tourist activity impacts their lives and what needs to be improved'.

This tendency may have presumably been justified by the fact that the majority of tourists visiting the island are mass tourists consuming cheap tourist packages that consume passively one-dimensional experiences (3Ss elements). In this regard, any 'local interaction' is part of the cheap mass tourist package that focuses mostly on these tourists' satisfaction, and only some 
niche forms of tourism met on the island appear to be more favourable for local communities, such as agricultural or natural tourism.

In addition, tourism suppliers in Cyprus adjust themselves to ethnic markets without maintaining the local culture and identity:

"When we had the English market, everything in the tourist offering was "Britishised" [around British culture], now that we have Russians, everything is "Russianised" [around Russian culture]...we don't have our own character'.

In this regard, a respondent representing the tourism policy adds that this tendency to adopt tourists' habits and culture for profit does not always have positive results:

'From various studies we had with tourists, even with Russians, we found out that they [tourists] are not interested for instance to go to a restaurant and eat Russian recipes. They want to see our identity and experience our culture'.

Regarding employment of locals in the island's tourism industry, respondents replied that indeed tourism offers an income to them. Yet, even in this case, there are social problems that alter their quality of life. In this respect, it was indicated that due to the seasonal character of Cypriot tourism, local employees in the tourism industry work for long hours during the summer period. They argue that for seven months employees do not have any free time to spend with their family. This is one of the main reasons that in tourist areas of Cyprus, such as Free Famagusta, the most important incidents of juvenile delinquency are noted: 'When both parents work in the tourism industry for many hours during the whole week, you have cases like these'. In the same vein, the long and stressful working hours create tension within the household and this situation can lead even towards increased divorces and family deconstruction. Finally, the 
unbalanced seasonal character of mass tourism generates employees of two gears; long and stressful working hours during the peak summer period and increased unemployment rates during the low peak one since many hotels and tourist enterprises suspend their operations then.

In environmental terms, tourism development has also raised serious queries regarding the life quality of the island's residents. As a respondent, representing the environmental bodies of the island, indicated: 'Extensive tourism development brought anarchy at the coasts of Cyprus. We did all these developments without any rules regarding the space aesthetics', or:

'The government does not put a limit on the tourism development of the island. This is wrong. For instance, it gave permission to the hotels in order for them to operate their own desalination plants. Every plant consumes vast amounts of electricity... it [the government] didn't put any permits regarding energy saving by the hotels or the reduction of water consumption. Water is precious for Cyprus and we cannot consume it like that...'.

and:

'We just want to bring tourists to make profit without thinking what will happen later on the place... we sacrifice Cypriot nature and environment to bring more and more tourists'.

A characteristic example of tourism development with diverse impacts, ramifications and contradictions for the island's residents and stakeholders was the construction of golf courses as a means to boost golf tourism during the winter months where seasonality is low. As mentioned in the interviews, such a development has significant effects mostly because it trespasses the natural resources that golf courses need, such as water and space, both of them limited in the case of Cyprus. Indeed, a successful and carefully planned golf development can generate profits for the owners-managers, as well as the government. However, as one of the respondents claims: 
'any building, let alone a golf development becomes an irreversible intervention' (in the environment). Through the interviews it was mentioned that golf courses require huge quantities of water for their maintenance while the large space used to develop a golf course could be used for other traditional types of development useful for the entire society and local economy (i.e., agriculture). Therefore, instead of capitalising on large investment projects that require significant amount of resources, it would be better to invest in further small scale activities that would benefit more harmonically the local community.

The above argument comes in line with another persistent problem in Cyprus, the dependence on the foreign capital and investment. According to the interviewees, while there is an effort to support foreign investments in the island by the government such as hotel and leisure complexes, golf courses and convention centres, there are questions regarding the actual effects of these projects on the overall residents' prosperity. As a respondent added, the matter of resources, especially water issues, does not only have economic impacts. Emphasis should also be placed on its social and environmental aspects. As stated, the agricultural sector on the island steadily declines and if it is not supported, its decay will lead to severe social problems. For instance, the respondent stated that it is preferable to give the water to many farmers in order to support their crops, and therefore enhance rural production, rather than giving it to the one or two businessmen of the golf industry for watering the grass of golf courses. Consequently, according to the respondent, the effectiveness of foreign investments for the local communities is questionable.

Nonetheless, do stakeholders of tourism and local communities have a say towards decision making? Respondents indicated that they do have a close cooperation with the government regarding matters of tourism development. However, they claim that they meet 
challenges in the implementation stage of the projects: 'When we say that we'll do something but in the end we do not do it, we damage our credibility and the confidence that private investors have on us'. In this regard, interviewees replied that there are serious problems in the coordination and implementation of plans. Two of the main reasons for this situation are the lack of organised bodies that would be responsible to monitor, control and guide projects on certain timelines as well the limited/inefficient communication among stakeholders. Bureaucracy also is a matter that was mentioned. As stated, there are numerous bodies dealing with tourism and each of them has its own agenda. This way the efficiency and credibility of any decision is uncertain.

Finally, findings indicate that even though residents' well-being is included in tourism planning, not many efforts have been made during the past decades in order to actually improve their quality of life. Furthermore, the dependence on mass tourism with emphasis on large projects and its economic benefits puts aside other important aspects of the local community such as culture, society and the environment. As such, locals working directly or indirectly in the tourism sector become part of a vicious circle where even though they earn some income, they are passive actors of plans during the implementation stage, while they become carriers of an unsustainable development that continues to invest in mass tourism and has negative impacts for the community. As an antidote to this problematic situation, tourism policy is responsible for the application of a series of measures that involve residents' prosperity.

\section{Tourism policy measures}

Based on the above findings, sustainable development premises, even though recognised as imperative by tourism policy, are not effectively applied. In regards to the policy measures taken for addressing the needs of the local community, respondents replied that policy measures are 
based on ad hoc decisions that only indirectly benefit locals. These decisions are mostly grounded on strategies that have a voluntarily, by the stakeholders, character and depend on the ability and willingness of each stakeholder to apply them. As an interviewed claimed:

'Stakeholders as individuals can make the difference in the effectiveness of policy measures... we were never organised to incorporate locals and there is lack of coordination among the stakeholders. Though, the local element plays an important role'.

As such, the limited coordination among the stakeholders of tourism generates inefficiencies regarding the application of measures that would ensure local prosperity and enhance sustainable development. Obviously, the dominance of mass tourism met on the island for more than fifty years complicates further this situation.

Hence, the traditional mass tourism development of Cyprus in conjunction with the series of its negative impacts and the recent decreased competitiveness of the island put on the map of planning more seriously the consideration of sustainable development and its angles concerning the environment, society and local economy. It is recognised by the respondents that the dominant form of tourism in Cyprus constrains sustainable development, while alternative tourism could be a measure for counterbalancing the existing situation: 'With alternative tourism, tourists are much more free to have options and therefore meet and appreciate better the local element'. However, it is on the hands of policy makers and tourist stakeholders to provide information as well as options to individual alternative tourists. These options need to take into consideration the local community's well-being. 
Regarding the measures that support the local residents' welfare, the increasing consideration of tourism policy towards sustainable development, during the recent years, seeks to address in a degree the local community's well-being. As stated:

'Recently -and due to the various studies that are conducted on this matter- it seems that locals are considered as an important characteristic in order for the culture of a place to be projected'.

The respondent suggests that this turn towards the inclusion of local views on the tourism product of the island, now makes them more central in the overall tourism planning:

'Since locals are recognised more, some qualitative criteria have now been established and legislated. A large part of these criteria includes topics that have to do with the local community, for instance gastronomy [...] There are two points: how do we help the community in a general level and how we help the local producers specifically'.

and:

'There are several programs such as the Cyprus Breakfast Awards. In order for hotels to gain this award, they need to have a series of local products which should not only be Cypriot but also should be from specific villages and specific districts on the island [...] Breakfast is a very important meal for Cypriot hotels. It is something that every tourist can eat and through it you can promote local culture and products. For each local product offered you need to provide information regarding the area of Cyprus it comes from and its history, even the name of the producer. Thus, tourists that consume the product(s) know exactly where they are from. The hotelier(s) needs to have also a trained person in order to provide more information to tourists in case they are interested in knowing more about the products, their history and their background. For instance, how this product was produced in the past, how do we eat it in Cyprus, etc.'.

According to the respondents, these types of programs can help considerably local communities. As stated: 
'There are many areas in Cyprus which their economy is based also on agriculture besides tourism. These areas organise festivals for local products every year. When festivals are happening in the area, hotels [of the area] need to offer the local product in their premises and to implement also promotional activities to promote both the festival as well as the local product. For instance, there is the festival of strawberry in Deryneia area that attracts thousands of people -both domestic and international visitors- and in the hotels you could see baskets full of strawberries and advertising material'.

Also, another effort to enhance local communities' welfare is the organisation of events that project local culture, by hotels in the local area. These events are not just one entertainment 'Cypriot night' (that hotels used to organise in the overall mass tourist package), but happenings where locals actively participate in common actions together with tourists. As stated in the interviews, tourists are encouraged to interact with locals in many activities such as the construction of a common project or visiting locals' houses in order for tourists to experience and learn the local lifestyle.

Along the same lines, a notable effort that takes place in the mountain area of Troodos is the creation of locally themed events, which celebrate local agricultural products and natural or traditional architectural features. These events are hosted in different villages and each features the celebration of a different aspect of local life or product. As the regional tourism officer said:

'We have created themed-events that aim to project the tradition and heritage of the region and attract visitors. For example, we have the rose festival, or the herbs and the apple ones. Also, we have developed the sports and fun festival, which projects that the region is suitable for a range of sports and outdoor recreational activities. Our goal is to establish a range of events throughout all year long.'

Another initiative by the Troodos Tourism Board is the imminent creation of travel packages that combine a range of tourist activities in the region and can thus, directly promote the whole region as an alternative tourism destination in Cyprus: 
'We are trying to create generic and special interest travel packages. Travel agents do not offer packages for Troodos because they do not have the same revenues as with the sea resorts. So we will play this role by creating and selling these travel packages. We have now the packages at pilot stage, which include visits to monasteries, traditional buildings, nature reserves, wine-making facilities, etc. We will soon have ready such packages ready to sell to the tourists.'

These actions bring closer tourists with locals while they enrich on the one hand the tourist experience and contribute on the other hand to the more efficient presentation of the local life and culture. These measures therefore, add to the overall sustainable development of the destination.

\section{Discussion and implications}

As derived from the findings, the overall planning of Cypriot tourism has been traditionally oriented towards achieving tourist satisfaction, treating locals mostly as a means to this goal rather than as important actors of tourism planning on the island. As such, a historical 'topdown' decision-making is still predominant with a subsequent 'outside-in' approach of tourism development directing tourism planning and development (Sofield, 2003; Zhang, Yamamura, \& Fujiki, 2013). However, the traditional form of tourism in Cyprus (mass tourism) is not competitive anymore and dissatisfaction both in economic as well as social terms for the host communities is noted. Moreover, the inability of mass tourism to face challenges such as decreased competitiveness and poor tourism product quality in a world where international and national crises characterise the external environment, brought the inherited problems of Cypriot tourism (i.e, seasonality, unbalanced development, etc.) up to the surface. This therefore, has emphasised further the need towards adopting more efficient strategies for social, economic and 
environmental sustainability, and consequently locals' prosperity. The task, hence, for Cyprus is to redress its long-term problems that have been increased due to the changing economic circumstances. Even though some policy measures have been adopted, it was found out that most of them are based on ad hoc decisions that only indirectly benefit local communities. As such, the Cypriot tourism policy should capitalise on any existent opportunity in order to implement comprehensive strategies that will build a robust ground for re-establishing Cyprus' competitiveness and sustainability having at their core residents' well-being through tourism development.

In this respect, tourism policy should invest in the diversification of its product-service mix, infused by locals' interests and characteristics. It is suggested that rural tourism development represents an opportunity to lead towards this direction. The chronic emphasis of Cyprus as a mass tourist destination has brought a series of negative impacts such as seasonality, unbalanced development limited to some coastal areas (Ioannides, 1992; Sharpley, 2002), leaving rural areas (and their residents) out of the focus (Boukas \& Ziakas, 2013a). Therefore, the majority of tourist movement in noted mostly on only five to six coastal areas while the largest rural areas of the island (i.e., Troodos region) are still unexploited (Ziakas \& Boukas, 2015). Rural tourism depends upon its capacity to provide an alternative form of development investing in the specific assets of a region that are capable of attracting special interest or niche tourism. Consequently, rural tourism could be a solution for both sustainable development as well as locals' prosperity, adopting an 'inside-out' approach of tourism planning.

A first expression of rural tourism development based on a range of special interest or alternative tourist activities is cultural heritage tourism. Undoubtedly, islands such as Cyprus are of great cultural heritage value. Cultural tourism is considered as a 'good' type of tourism which 
aids to deal with the 'bad' type of mass tourism and its effects (Richards, 2001). Moreover, cultural tourism conglomerates particular qualities that make it an appropriate form of tourism development (Boukas, 2012); it devotes and presents cultural ideas of local people, it is small scale and frequently targets up-markets, it presents concepts expressed in monuments and surrounding locations (ICOMOS, 2003). Furthermore, cultural tourism adds to cultural revitalisation in host communities, as it generates pride and interest in local community traditions (Misiura, 2006; Piccard, 1996). In this regard, cultural tourism not only can directly employ locals but can also use them as the main planners and carriers of cultural heritage products and activities. As Robinson and Smith (2006, p.13) argue: 'In situations where there is a more level playing field between stakeholders, cultural tourism is arguably easier to establish'. The authors add that a 'bottom-up' approach in cultural heritage tourism can be encouraged and that an effective framework for community involvement needs also to incorporate the important intangible elements of community and tourism development such as quality of life and pride of a place.

In line with cultural tourism, natural tourism could also be another aspect that can bring a more balanced development and quality of life for the local residents. Natural environment sightseeing and outdoor recreational activities, including hiking, visits to nature reserves and waterfalls, bird watching, cycling, and skiing, can generate small scale niche tourists and can lead to residents' well-being. In this respect, ecotourism is also another element of great importance. However, as Scheyvens (1999, p.245) argues: 'Ecotourism ventures should only be considered successful if local communities have some measure of control over them and if they share equitably in the benefits emerging from ecotourism activities'. The author suggests an empowerment framework that provides a mechanism within which the efficiency of ecotourism 
initiatives, in terms of their effects on local communities, is determined. This framework utilises four levels of empowerment: economic, social, psychological and political and for each level it measures the signs of empowerment and signs of disempowerment of a community. The author concludes that ecotourism should project both conservation and development at the local level.

Finally, another aspect of rural tourism that could project the prosperity of residents in combination with the aforementioned pillars is the enhancement of themed events and festivals, featuring the traditional products and natural qualities of the area. Depending on the existing natural and cultural resources or other characteristics of a rural area, policies for the development of rural tourism utilise events and festivals as key attractions (Butler, Hall, \& Jenkins, 1998; Higham \& Ritchie, 2001; Roberts \& Hall, 2001). The positive impacts of festivals spread well beyond generating tourism income and incorporate reinforcing the social capital of rural communities (Fortes, 1936; Walter, 1981; Derrett, 2003; Arcodia \& Whitford, 2006) and enhancing the quality of small-town life (De Bres \& Davis, 2001; Picard \& Robinson, 2006; Brennan-Horley, Connell, \& Gibson, 2007). Moreover, small scale themed-events and festivals can deliver a social experience to local people, such as celebrating local identity and shared values (Derrett, 2003), and hence, they can be used as a marketing tool to improve the image of the host community and attract tourist visitation (Janiskee \& Drews, 1998).

However, in order for the tourism policy to successfully adopt the above measures it needs to face also a series of challenges. According to the interviews, there are significant structural challenges that obstruct the establishment of new types of tourism development that would lead to the creation of a competitive sustainable destination (i.e., rural tourism). The enormous bureaucratic system makes decision-making and implementation strategies challenging. In the same lines, even though stakeholders cooperate with tourism policy, 
problems with the implementation of decision making are obvious. Moreover, the improved communication among stakeholders as well as their full engagement in the decision-making regarding tourism matters is imperative. As such, tourism policy should initiate communication schemes in order to motivate local stakeholders to reach an agreement through negotiating tradeoffs for the equal distribution of tourism benefits that will satisfy environmental, social, and economic concerns, therefore leading to sustainability and community well-being.

Above all, however we need to understand that in the case of islands such as Cyprus (with their long history of development as coastal mass tourism destinations) any effort for developing small scale tourism (i.e., rural tourism) in order to benefit the local community, dictates the repositioning and rebranding of the island's tourism product-service mix. The study demonstrates that islands have a great number of cultural and natural resources that can be used for improving their image and projecting their local identity worldwide. However, there is a need by the tourism policy to realise that even in the case of alternative forms of tourism, if visitation keeps increasing without any regulation, then their development could lead also to the excess of the carrying capacity limits that will eventually diminish the quality of the tourism product and local well-being, hence causing both visitors' dissatisfaction and residents' frustration. As such, policies for tourism development need to be built upon a well-being sustainable framework that derives from actions to improve local quality of life and cater for the economic, social and environmental needs of island destinations.

\section{Concluding remarks}

The findings of this study indicate that Cyprus tourism policy addresses only indirectly the wellbeing of its residents. Since this is the result of following a diachronic 'outside-in' mass tourism 
development model, a policy re-orientation is imperative that will place at its core the residents' well-being. As shown, an 'inside-out' approach may become feasible providing that tourism policy focuses on alternative forms of tourism development such as rural tourism and special interest tourism capitalising on the island's intact cultural and natural assets. These represent opportunities to develop for instance, locally-themed festivals, cultural heritage tourism or nature tourism that foster local values, traditions and identities providing recreational opportunities and revitalising the social fabric of local communities, thereby contributing directly to residents' well-being. In other words, Cyprus needs to reconfigure its tourism product and regain its competitiveness, but for this to be effective and sustainable, tourism policy should remedy the 'top-down' and bureaucratic planning processes that create severe challenges for the sustainable development of the island's tourism sector, exacerbated by the continuous economic crisis and mass tourism negative impacts. In this regard, the adoption of an 'inside-out' approach can explicitly emphasise and enable 'bottom-up' decision-making by empowering residents to partake in tourism planning of local communities with the purpose to improve their quality of life.

Broadly, it is argued that an 'inside-out' approach is appropriate for small island destinations in order to protect their resources and physiognomy. From this perspective, tourism is viewed as an outcome stemming from the kind of development that locals want for themselves in order to improve their quality of life. This entails the socio-cultural revitalisation and subsequent identity formation of islands that can in turn help build a distinctive destination brand. In practical terms, community participation and empowerment of residents in tourism planning is essential for re-shaping the tourism product of island destinations. Future work is needed to 
explore the conditions and the means that small islands can be repositioned and rebranded driven by a local focus aimed at enhancing residents' well-being.

\section{References}

Archontides, Y.K. (2007). Review of Cypriot tourism: Through a series of articles, interviews and speeches. Athens: A.A. Livani [in Greek].

Arcodia, C., \& Whitford, M. (2006). Festival attendance and the development of social capital. Journal of Convention \& Event Tourism, 8(2), 1-18.

Aretano, R., Petrosillo, I., Zaccarelli, N., Semeraro, T., \& Zurlini, G. (2013). People perception of landscape change effects on ecosystem services in small Mediterranean islands: A combination of subjective and objective assessments. Landscape and Urban Planning, 112, (April), 63-73.

Arksey, H., \& Knight, P. (1999). Interviewing for social scientists: An introductory resource with examples. London: Sage.

Azzopardi, E., \& Nash, R. (2015, In Press). A framework for island destination competitiveness perspectives from the island of Malta. Current Issues in Tourism, DOI: $10.1080 / 13683500.2015 .1025723$

Bastin, R. (1988). Small island tourism: development of dependency? Development Policy Review, 2(1), 79-90.

Boukas, N. (2012). "Young faces in old places": perceptions of young cultural visitors for the archaeological site of Delphi. Journal of Cultural Heritage Management and Sustainable Development, 2(2), 164-189.

Boukas, N., Boustras, G., \& Sinka, A. (2012). Golf tourism: The case of Cyprus. In O. Moufakkir, \& P.M. Burns (Eds.), Controversies in tourism (pp. 144-59). Oxfordshire: CABI.

Boukas, N., \& Ziakas, V. (2013a). Impacts of the global economic crisis on Cyprus tourism and policy responses. International Journal of Tourism Research, 15(4), 329-345. 
Boukas, N., \& Ziakas, V. (2013b). Exploring perceptions for Cyprus as a sustainable golf destination: Motivational and attitudinal orientations of golf tourists. International Journal of Sport Management and Marketing, 14(1-4), 39-70.

Boukas, N., \& Ziakas, V. (2014). A chaos theory perspective of destination crisis and sustainable tourism development in islands: the case of Cyprus. Tourism Planning \& Development, 11(2), 191-209.

Brennan-Horley, C., Connell, J., \& Gibson, C. (2007). The Parkes Elvis Revival Festival: Economic development and contested place identities in rural Australia. Geographical Research, 45(1), $71-84$

Butler R. (2008). Islands. In M. Lück (Ed.), Encyclopaedia of tourism and recreation in marine environments (p. 254), Wallingford: CABI.

Butler, R., Hall, C.M., \& Jenkins, J. (Eds.) (1998). Tourism and recreation in rural areas. Chichester, UK: Wiley.

Buzinde, C. N., Kalavar, J. M., \& Melubo, K. (2014). Tourism and community well-being: The case of the Maasai in Tanzania. Annals of Tourism Research, 44, 20-35.

Carlsen, J., \& Butler, R. (2011). Introducing sustainable perspectives of island tourism. In J. Carlsen, \& R. Butler (Eds.), Island tourism: Sustainable perspectives (pp. 1-8). Oxfordshire: CABI.

Chang, T.C., Milne, S., Fallon, D., \& Pohlmann, C. (1996). Urban heritage tourism: The globallocal nexus. Annals of Tourism Research, 23(2), 284-305.

Cole, S. (2009). A logistic tourism model, resort cycles, globalization, and chaos. Annals of Tourism Research, 36(4), 679-714.

Croes, R. (2011). Measuring and explaining competitiveness in the context of small island destinations. Journal of Travel Research, 50(4), 431-442.

Currie, C., \& Falconer, P. (2014). Maintaining sustainable island destinations in Scotland: The role of the transport-tourism relationship. Journal of Destination Marketing \& Management, 3(3), $162-172$.

De Bres, K., \& Davis, J. (2001). Celebrating group and place identity: A case study of a new regional festival. Tourism Geographies, 3(3), 326-337.

Del Chiappa, G., \& Abbate, T. (2015, In Press). Island cruise tourism development: a resident's perspective in the context of Italy. Current Issues in Tourism, DOI: $10.1080 / 13683500.2013 .854751$ 
Derrett, R. (2003). Making sense of how festivals demonstrate a community's sense of place. Event Management, 8(1), 49-58.

dos Santos, E.R.M. (2014). Destination mutant brands: An empirical perspective of tourism professionals and host community to create Mutant Brand Cape Verde. Journal of Destination Marketing \& Management, 3(1), 68-78.

Fortes, M. (1936). Ritual festivals and social cohesion in the Hinterland of the Gold Coast. American Anthropologist, 38(4), 590-604.

Gotham, K.F. (2005). Tourism from above and below: globalization, localization and New Orleans's Mardi Gras. International Journal of Urban and Regional Research, 29(2), 309-326.

Graci, S., \& Dodds, R. (2010). Sustainable tourism in island destinations. London: Earthscan.

Graci, S. (2013). Collaboration and partnership development for sustainable tourism. Tourism Geographies, 15(1), 25-42.Greek Statistics (2014). Arrivals of international tourists: January - Necember, $2013 . \quad$ Retrieved from http:/www.eot.gr/sites/default/files/files basic pages/ELSTAT 2013.pdf (25.2.2015).

Grix, J., (2001). Demystifying postgraduate research. Birmingham: A\&C Black.

Gutiérrez, L.R. (2015). The environmental effects of tourism architecture on island ecosystem in Cayo Guillermo, Cuba. Journal of Environmental Protection, 6(09), 1057-1065.

Hadjikakou, M., Chenoweth, J., Miller, G., Druckman, A., \& Li, G. (2014). Rethinking the economic contribution of tourism: Case study from a Mediterranean island, Journal of Travel Research, 53(5), 610-624.

Higham, J., \& Ritchie, J.R.B. (2001). The evolution of festivals and other events in rural southern New Zealand. Event Management, 7(1), 39-49.

ICOMOS (2003). Tourism at world heritage cultural sites: The site manager's handbook. Washington: International Council on Monuments and Sites (ICOMOS) and the World Tourism Organisation (WTO).

Ioannides, D. (1992) Tourism development agents: The Cypriot resort cycle. Annals of Tourism Research. 19(4): 711-731.

Jaafar, M., \& Maideen, S.A. (2012). Ecotourism-related products and activities, and the economic sustainability of small and medium island chalets. Tourism Management, 33(3), 683-691. 
Janiskee, R.L., \& Drews, P. L. (1998). Rural festivals and community reimaging. In R. Butler, C.M. Hall, C.M., \& J. Jenkins (Eds.), Tourism and recreation in rural areas (pp. 157-175). Chichester, UK: Wiley.

Jogaratnam, G., \& Law, R. (2006). Environmental scanning and information source utilization: exploring the behavior of Hong Kong hotel and tourism executives. Journal of Hospitality \& Tourism Research, 30(2), 170-190.

Keener, V. (2013). Climate change and pacific islands: indicators and impacts: report for the 2012 pacific islands regional climate assessment. Washington: Island press.

Kelly, E.D., \& Becker, B. (2000). Community planning: An introduction to the comprehensive plan. Washington, DC: Island Press.

King, N. (1994). The qualitative research interview. In C. Cassell, \& G. Symon (Eds.), Qualitative methods in organizational research: A practical guide (pp. 14-38). London: Sage.

Kusel, J., \& Fortmann, L.P. (1991). What is community well-being? Well-being in forest-dependent communities (Volume I). In J. Jusel, \& L. Fortman, (Eds.), Forest and rangeland resources assessment program (pp.1-45), CA, Sacramento: Department of Forestry, Forest and Rangeland Assessment Program.

Lean, G. (1994). Early warnings from small islands. Choices, 3(3), 27-30.

Lewis-Cameron, A., \& Roberts, S. (2010). Small island developing states: issues and prospects. In A. Lewis-Cameron, \& S. Roberts (Eds). Marketing island destinations: Concepts and cases (pp.1-8), London: Elsevier.

Lim, C.C., \& Cooper, C. (2009). Beyond sustainability: optimising island tourism development. International Journal of Tourism Research, 11(1), 89-103.

McElroy, J. L., \& De Albuquerque, K. (1998). Tourism penetration index in small Caribbean islands. Annals of Tourism Research, 25(1), 145-168.

Meethan, K. (2001). Tourism in global society: Place, culture, consumption. New York: Palgrave.

Misiura, S. (2006). Heritage marketing. Oxford: Butterworth-Heinemann.

Nawijn, J., \& Mitas, O. (2012). Resident attitudes to tourism and their effect on subjective wellbeing: the case of Palma De Mallorca. Journal of Travel Research, 51(5), 531-541.

Niles, D., \& Baldacchino, G. (2011). Introduction: on island futures. In D. Niles, \& G. Baldacchino (Eds.), Island futures: Conservation and development across the Asia-Pacific region (pp.1-8). New York: Springer. 
Paci, R., \& Marrocu, E. (2014). Tourism and regional growth in Europe. Papers in Regional Science, 93(S1), S25-S50.

Piccard, M. (1996). Bali: Cultural tourism and touristic culture. Singapore: Archipelago Press.

Picard, D., \& Robinson, M. (Eds.) (2006). Festivals, tourism and social change. Clevedon, UK: Channel View.

Pratt, S. (2015). The economic impact of tourism in SIDS. Annals of Tourism Research, 52(May), $148-160$.

Pratt, S., \& Harrison, D. (Eds.) (2015). Tourism in Pacific islands: Current issues and future challenges. Oxon: Routledge.

Ribeiro, M. A., Valle, P. O. D., \& Silva, J. A. (2013). Residents' attitudes towards tourism development in Cape Verde Islands. Tourism Geographies, 15(4), 654-679.

Ridderstaat, J., Croes, R., \& Nijkamp, P. (2014). The tourism development-quality of life nexus in a small island destination. Journal of Travel Research, 16(5), 472-487.

Ridderstaat, J., Oduber, M., Croes, R., Nijkamp, P., \& Martens, P. (2014). Impacts of seasonal patterns of climate on recurrent fluctuations in tourism demand: Evidence from Aruba. Tourism Management, 41, 245-256.

Robbins, E. (1994). Trouble in Paradise. Environmental Magazine, 5(3), 36-40.

Roberts, L., \& Hall, D. (2001). Rural tourism and recreation. Wallingford, UK: CABI.

Robinson, M., \& Smith, M.K. (2006). Politics, power and play: The shifting contexts of cultural tourism. In M.K. Smith \& M. Robinson (Eds.), Cultural tourism in a changing world: Politics, participation and (re) presentation (pp.1-17). Clevedon: Channel View Publications.

Rodríguez, J.R.O., Parra-López, E., \& Yanes-Estévez, V. (2008). The sustainability of island destinations: Tourism area life cycle and teleological perspectives. The case of Tenerife. Tourism Management, 29(1), 53-65.

Saveriades. A. (2000). Establishing the social tourism capacity for the tourist resorts of the East Coast of the Republic of Cyprus. Tourism Management, 21(2), 147-56.

Scheyvens, R. (1999). Ecotourism and the empowerment of local communities. Tourism management, 20(2), 245-249.

Scott, J. (1990). A Matter of record, documentary sources in social research. Cambridge: Polity Press. 
Seetanah, B. (2011). Assessing the dynamic economic impact of tourism for island economies. Annals of Tourism Research, 38(1), 291-308.

Sharpley, R. (2002). Rural tourism and the challenge of tourism diversification: The case of Cyprus. Tourism Management, 23(3): 233-244.

Sharpley, R. (2009). Tourism development and the environment: Beyond sustainability? London: Earthscan.

Sharpley, R. (2012). Island tourism or tourism on islands? Tourism Recreation Research, 37(2), $167-$ 172.

Sharpley, R., \& Ussi, M. (2014). Tourism and governance in small island developing states (SIDS): the Case of Zanzibar. International Journal of Tourism Research, 16(1), 87-96.

Shaw, G., \& Williams, A. (2004). Tourism and tourism spaces. London: Sage.

Silverman, D. (2001). Interpreting qualitative data: Methods for analyzing talk, text, and interaction ( $2^{\text {nd }}$ ed.). London: Sage.

Sofield, T.H. (2003). Empowerment for sustainable tourism development. Oxford: Elsevier.

Stathatou, P.M., Gad, F.K., Kampragou, E., Grigoropoulou, H., \& Assimacopoulos, D. (2015). Treated wastewater reuse potential: mitigating water scarcity problems in the Aegean islands. Desalination and Water Treatment, 53(12), 3272-3282.

Teo, P., \& Li, L.H. (2003). Global and local interactions in tourism. Annals of Tourism Research, $30(2), 287-306$.

Theobald, W.F. (2005). Global tourism ( $3^{\text {rd }}$ edition). Burlington: Elsevier.

Tsartas P. (2003). Tourism development in Greek insular and coastal areas: Sociocultural changes and crucial policy issues. Journal of Sustainable Tourism, 11(2\&3), 116-132.

Walter, L. (1981). Social strategies and the fiesta complex in an Otavaleno community. American Ethnologist, 8(1), 172-185.

Weiss, R.S. (1994). Learning from strangers: The art and method of qualitative interview studies. New York: Free Press.

Wilson, P.A. (1996). Empowerment: Community economic development from the inside out. Urban Studies, 33(4-5), 617-630.Yin, R.K. (2009). Case study research: Design and methods (4 ed.). Thousand Oaks, CA: Sage. 
Zhang, T. X., Yamamura, T., Fujiki, Y., Diaz, P., \& Schmitz, M.F. (2013). Can vernacular buildings survive with traditional life inside and tourism outside? In P. Diaz, \& M.F. Schmitz, Tourism today Vol. 1: Cultural Tourism (pp. 83-92). Southampton: WIT Press.

Ziakas, V., \& Boukas, N. (2013). Extracting meanings of event tourist experiences: a phenomenological exploration of Limassol carnival. Journal of Destination Marketing \& Management, 2(2), 94-107.

Ziakas, V., \& Boukas, N. (2015). 'Over the hills and far away' from the coast: Rural island tourism in the mountains and alternative regional development. In K. Dashper (Ed.), Rural tourism: An international perspective (pp. 390-409), Newcastle upon Tyne: Cambridge Scholars.

Ziakas, V., \& Costa, C.A. (2010). 'Between theatre and sport' in a rural event: Evolving unity and community development from the inside-out. Journal of Sport and Tourism, 15(1), 7-26. 
Table 1: Background of Interviewees

\begin{tabular}{|c|l|c|c|}
\hline Respondent & \multicolumn{1}{|c|}{ Institutional Domain } & Role & Age \\
\hline 1 & Tourism policy & Officer & $>35$ \\
\hline 2 & Tourism policy & Officer & $>35$ \\
\hline 3 & Tourism policy & Manager & $>40$ \\
\hline 4 & Travel agent association & Manager & $>55$ \\
\hline 5 & Travel agent association & Manager & $>45$ \\
\hline 6 & Hotel association & Officer & $>55$ \\
\hline 7 & Hotel association & Manager & $>55$ \\
\hline 8 & Investment agency & Manager & $>50$ \\
\hline 9 & Tourism businesses association & Manager & $>50$ \\
\hline 10 & Environmental group & Manager & $>35$ \\
\hline 11 & Rural development association & & \\
\hline
\end{tabular}


Table 2: Interview Guide

\section{Core Questions}

-What is the position and importance of residents' well-being for Cyprus overall tourism product mix as well as the pertinent types of tourist activities currently offered?

-What are the tourism policy measures that aim to enhance residents' quality of life?

-What are the effects of tourism development on residents' well-being?

-How does tourism planning contribute to the sustainability of Cyprus?

-What is the potential of alternative forms of tourism to be leveraged for sustainable tourism development?

-What are the challenges and opportunities to develop tourism products and services that enhance residents' quality of life? 